\title{
Approximation of the process of changes in deformation of land surface using artificial neural networks
}

\author{
Maria Mrówczyńska ${ }^{1, *}$, and Jacek Sztubecki ${ }^{2}$ \\ ${ }^{1}$ University of Zielona Góra, Institute of Building Engineering, Faculty of Civil Engineering, Architecture and Environmental \\ Engineering, 1 Szafrana St., 65-516 Zielona Góra, Poland \\ ${ }^{2}$ University of Science and Technology, Faculty of Civil and Environmental Engineering and Architecture, 7 prof. S. Kaliski St., \\ 85-796 Bydgoszcz, Poland
}

\begin{abstract}
Artificial neural networks are an interesting method for modelling phenomena, including spatial phenomena, which are difficult to describe with known mathematical models. The properties of neural networks enable their practical application for solving such problems as: approximation, interpolation, identification and classification of patterns, compression, prediction, etc. The article presents the use of multilayer feedforward artificial neural networks for describing the process of changes in land surface deformation in the area of the Legnica-Głogów Copper Mining Centre, located in the southern part of the Fore Sudetic Monocline. Results provided by geodesic monitoring, which consists of land surveying and interpreting data obtained in this way, are undoubtedly significant in terms of identifying the impact of mining on the land surface the results of measurements carried out by precise levelling in the years 19672014 were used to determine changes in land deformation in the Legnica-Głogów Copper Mining Centre. The concept of a flexible reference system was used to assess the stability of points in the measurement and control network stabilized in order to determine vertical displacements. However, the reference system itself was identified on the basis of the critical value of the increment of the square of the norm of corrections to the observations.
\end{abstract}

\section{Introduction}

A commonly used method of mathematical description of processes and phenomena is linear modelling, which brings favourable results because it provides a good description of the optimization strategy used in models of this type. However, when there is no basis for the use of linear approximation, and non-linear models bring unfavourable results, artificial neural networks can be used because they construct models needed by the user by learning from examples provided by the user [1, 2]. At present, there are three basic directions of research on neural networks $[3,4]$ :

- classic neural networks (including the multilayer perceptron used in this paper);

- SVM (Support Vector Machine) networks,

- neural networks using fuzzy logic (fuzzy neural networks).

In this paper neural networks trained with the backpropagation algorithm method were used for constructing a geometrical displacement model on the basis of geodesic measurements. Geodesic measurements provide a large amount of data about the impact of mining on the rock mass and the land surface, which also makes it easier to explain the process of deformation of engineering structures. Geodesic monitoring, which consists of measurements and their interpretation, makes it possible to draw conclusions about the dynamics of the occurrence of deformations. A typical symptom of deformation are displacements of measurement points located in the research area, caused by changes in the ground-water conditions or by mining [5].

\section{Methods}

Multilayer feedforward artificial neural networks (multilayer perceptron) can generalize acquired knowledge, i.e. a network that is properly trained on a training data set should generate the expected results after data from the testing set are introduced at the input. Therefore, it is possible to say that a network trained on a set of training patterns transfers its knowledge onto the testing sets as a measure of the ability to generalize. In order to obtain correct generalization, the training process should meet the following conditions [6]:

- the training data should be representative, and their number should be greater than the number of network parameters (weights) that are being determined,

- the network architecture should be as simple as possible, i.e. possibly with the smallest number of weights (an excessive number of neurons in the

* Corresponding author: m.mrowczynska@ib.uz.zgora.pl 
hidden layer does not improve the quality of data processing),

- the most effective algorithms should be used in the training process, and they should stop operating when the minimum error is obtained in the testing set.

In a multilayer perceptron network neurons are arranged in layers and only successive layers are connected (Fig.1), for this reason the signal flows in the network only in one direction. The basic problems that should be solved in order to obtain satisfying results while training networks with the error backpropagation method are:

- initial data analysis of the (division of the data set into the training set and the testing set, methods for normalizing the data set),

- network architecture (the number of hidden layers and the number of neurons in these layers), initial selection of network weights, optimum selection of training parameters $\eta$ and $\lambda$, a proper network training process (selection of activation functions, selection of a gradient optimization method, adoption of a criterion for stopping the algorithm).

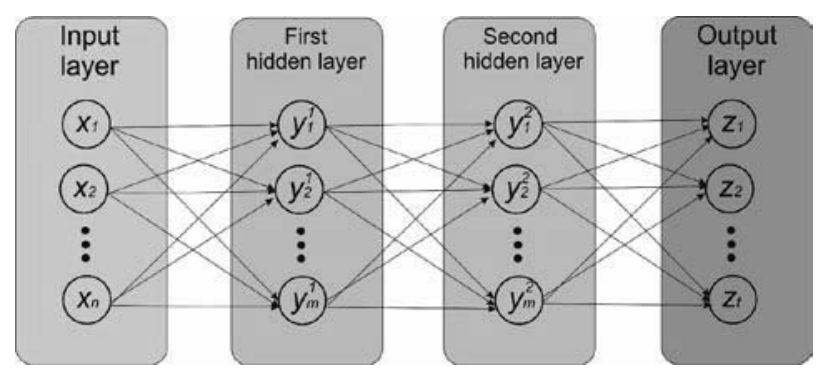

Fig. 1. The structure of a multilayer neural network.

The process of training a neural network is a supervised process (training with a teacher) with the use of gradient optimization methods. It is effected by minimizing the objective function $E(x, w)$, most frequently defined as

$$
E(\mathbf{w}, \mathbf{x})=\sum_{i=1}^{m}\left(\mathbf{z}\left(\mathbf{x}_{i}, \mathbf{w}\right)-\mathbf{d}_{i}\right)
$$

where: $\mathbf{w}$ - the matrix of weights, $\mathbf{x}$ - the vector of input signals, $\mathbf{d}$ - the vector of signals expected at the output, $\mathbf{z}$ - the output signal obtained as a result of network operation, $m$ - the number of training pairs.

Training a network consists in selecting weights of synaptic connections that ensure that the objective function reaches minimum values. Since it is assumed that the activation function used for training a network is a continuous function (usually bipolar or unipolar), gradient methods can be used for minimizing the objective function.

In gradient methods the training process consists in determining a direction of minimization specified by the vector $\mathbf{p}$, which depends on the values of weights of particular synaptic connections [7]. Therefore, the process of correction of the vector of weights in particular iterations ( $k$-iteration number) is as follows:

$$
\mathbf{w}(k+1)=\mathbf{w}(k)+\eta \mathbf{p}(k)
$$

where: $\eta$ is an arbitrary training coefficient adopted from the range $(0,1)$. The method for determining the direction of minimization $\mathbf{p}$ in particular training cycles $k$ for the most frequently used gradient optimization methods is presented in Table 1.

Table 1. The method for determining the direction of

\begin{tabular}{|c|c|}
\hline Gradient optimization method & $\begin{array}{l}\text { The minimizing } \\
\text { direction } \mathbf{p}(k)\end{array}$ \\
\hline Steepest descent method & $-\mathbf{g}(\mathbf{w})$ \\
\hline Quasi-Newton algorithm & $-[\mathbf{H}(\mathbf{w})]^{-1} \mathbf{g}(\mathbf{w})$ \\
\hline Conjugate gradient method & $-\mathbf{g}(\mathbf{w})+\beta \mathbf{p}(\mathrm{k}-1)$ \\
\hline Levenberg-Marquardt algorithm & $-[\mathbf{G}(\mathbf{w})]^{-1} \mathbf{g}(\mathbf{w})$ \\
\hline $\begin{array}{l}\text { Resilient backpropagation } \\
\text { algorithm }\end{array}$ & $-\operatorname{sgn}(\mathbf{g}(\mathbf{w}))$ \\
\hline \multicolumn{2}{|c|}{$\begin{array}{l}\text { where: } \\
\mathbf{g}(\mathbf{w}) \text { - vector of the gradient in the direction } \mathbf{p} \\
{[\mathbf{G}(\mathbf{w})]^{-1} \text { - matrix of the approximated Hessian }} \\
{[\mathbf{H}(\mathbf{w})]^{-1} \text { - broad matrix of Hessian }} \\
\beta \text { - the conjugation coefficient dependent on the value of the } \\
\text { gradient in two successive iterations }\end{array}$} \\
\hline
\end{tabular}
minimization.

\section{Results}

During the process of identification and analysis of the impact of mining on the rock mass and land surface, the results of geodesic measurements are especially important, in particular those that make it possible to determine the vertical displacements of measurement and control points of networks set up in mining areas. Geodesic measurements provide data and information describing the impact of mining on the land surface [8], which makes it much easier to explain the process of deformation of engineering structures located in hazard areas.

In order research the impact of mining on the land surface, geodesic measurements were carried out in the Legnica-Głogów Copper Mining Centre, located in the southern part of the Fore Sudetic Monocline (southwestern Poland) [9]. The approximation of land deformation in the Legnica-Głogów Copper Mining Centre was carried out with the use of artificial intelligence and based on the results from four measurement campaigns conducted in the years 19672014. In that area of about 75,000 ha the measurement and control network had 137 points that were connected with one another with 164 observations (the observations were carried out with the precise levelling method). A diagram of the structure of the geometric displacement model is presented in Fig. 2.

The approximation of land deformation was carried out with the use of multilayer feedforward neural networks, which were trained with the use of all the gradient optimization methods listed in Table 1 and for 
different network architecture variants (the number of hidden layers and the number of neurons in the layers). The training set consisted of $70 \%$ of all points of the measurement and control network, which had been randomly qualified for this set. The other $30 \%$ of points constituted the testing set, which did not participate in the training process. With the correct selection of the structure and parameters of the network, the quality of the operation of the network can be assessed on the basis of the RMSE (the root-mean-square-error) for the testing set. This error is described as follows [10]:

$$
R M S E=\sqrt{\frac{1}{m} \sum_{1}^{m}\left(z_{i}-d_{i}\right)^{2}}
$$

where $m$ is the number of members in the testing set (or training set), $d$ - the expected value of the output signal, $Z$ - the value of the output signal obtained as a result of the operation of the neural network.

The results of the network training and testing process, including the most favourable architecture, are presented in Table 2 and in Figs. 3 and 4. The graphical interpretation of the results of the approximation of the land deformation process is concerned with the most and the least favourable result of the network training process.

\section{Calculation of changes in altitude differences}

In this paper changes in altitude differences were determined for the years 1967-2014
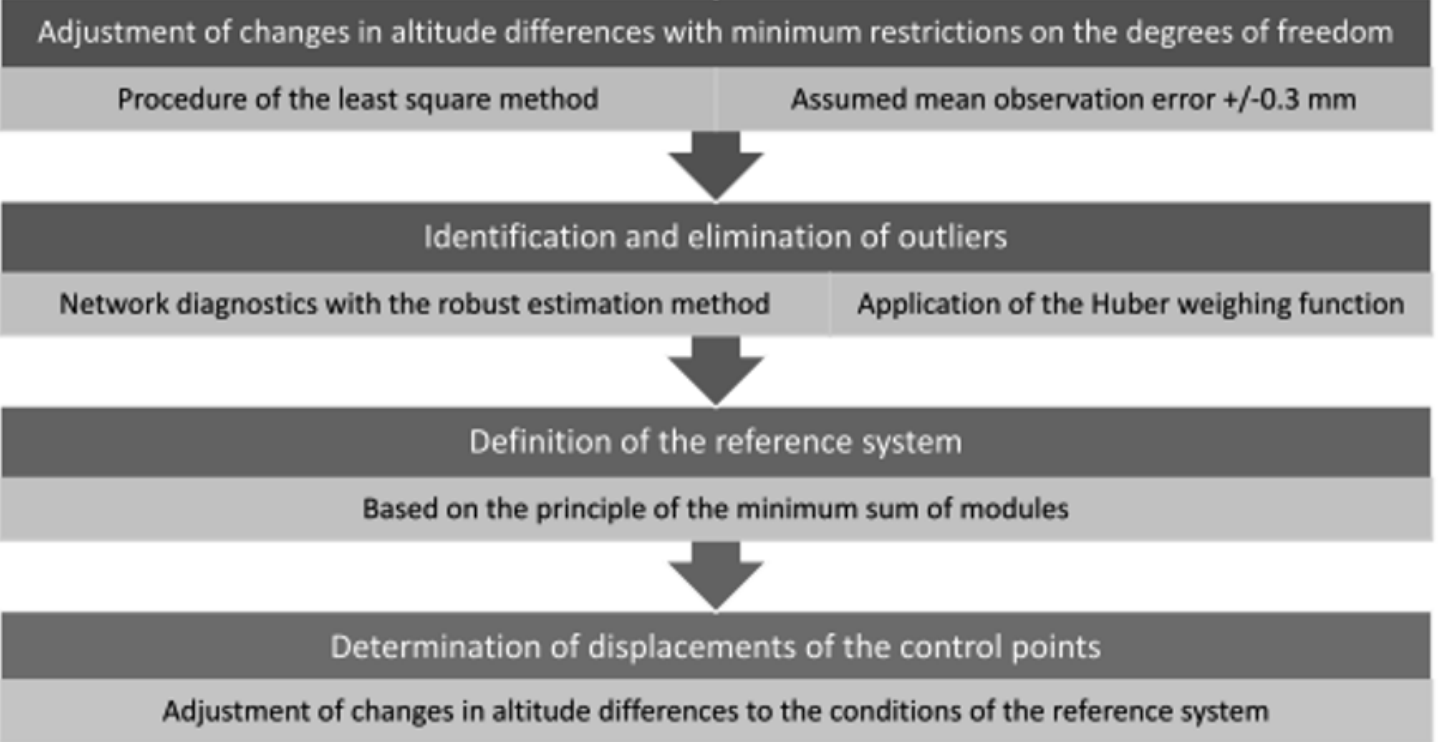

Fig. 2. A diagram of the structure of the geometric displacement model.

Table 2. The results of the neural network training and testing process.

\begin{tabular}{|c|c|c|c|}
\hline \multirow{2}{*}{ Gradient optimization method } & \multirow{2}{*}{ Network architecture } & \multicolumn{2}{c|}{ root-mean-square-error RMSE [m] } \\
\cline { 3 - 4 } & & Training set & Testing set \\
\hline Steepest descent method & 2_8_3_1 & 0.29 & 0.37 \\
\hline Quasi-Newton algorithm & 2_7_2_1 & 0.21 & 0.23 \\
\hline Conjugate gradient method & 2_7_4_1 & 0.13 & 0.15 \\
\hline Levenberg-Marquardt algorithm & 2_7_3_1 & 0.17 & 0.18 \\
\hline Resilient backpropagation algorithm & 2_7_1 & 0.15 & 0.17 \\
\hline $2^{\text {nd }}$ degree polynomial & - & 0.33 & 0.35 \\
\hline Kriging & - & 0.12 & 0.14 \\
\hline Spline & - & 0.11 & 0.13 \\
\hline
\end{tabular}




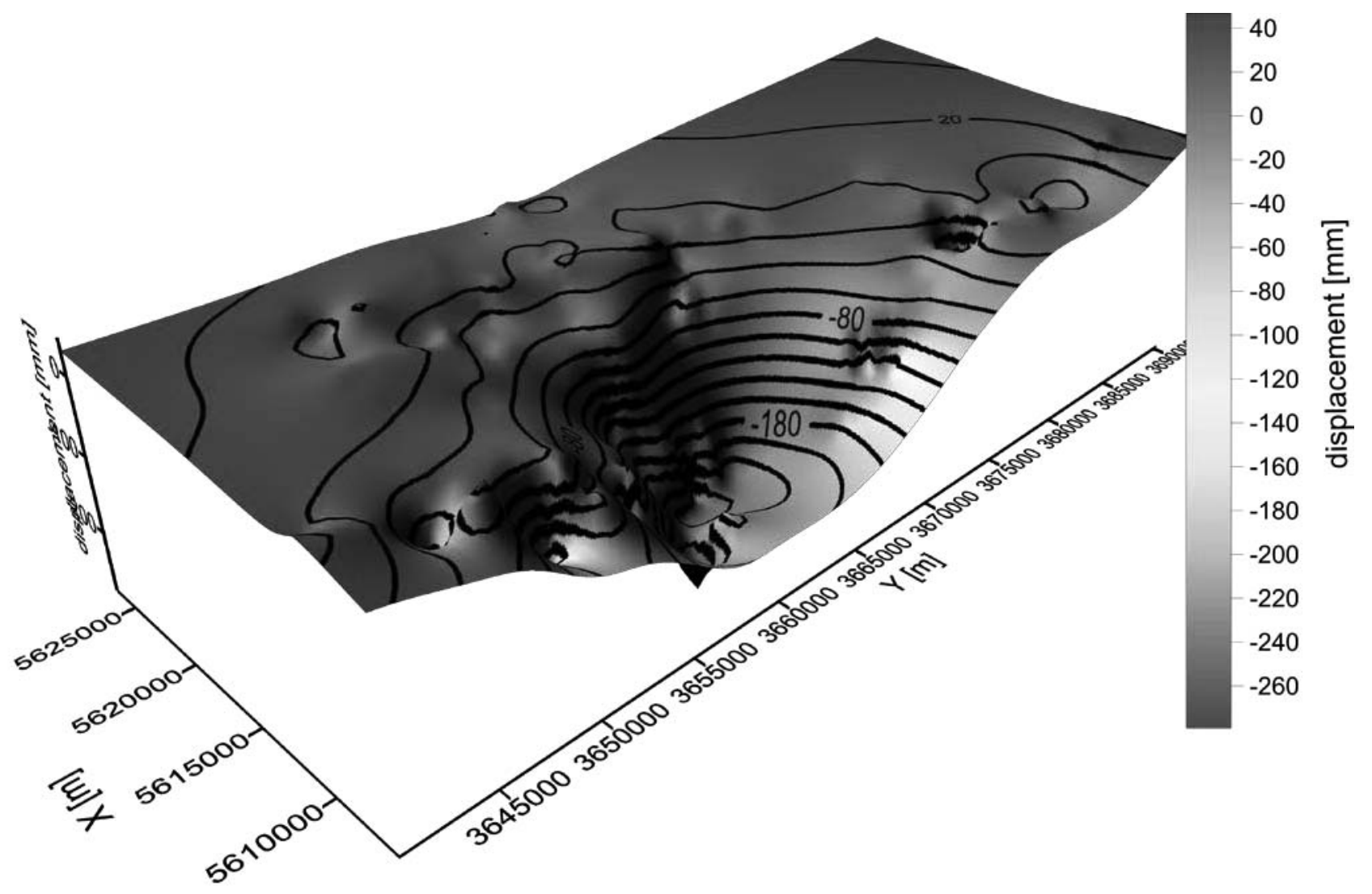

Fig. 3. A geometric model of a land deformation: conjugated gradient method.

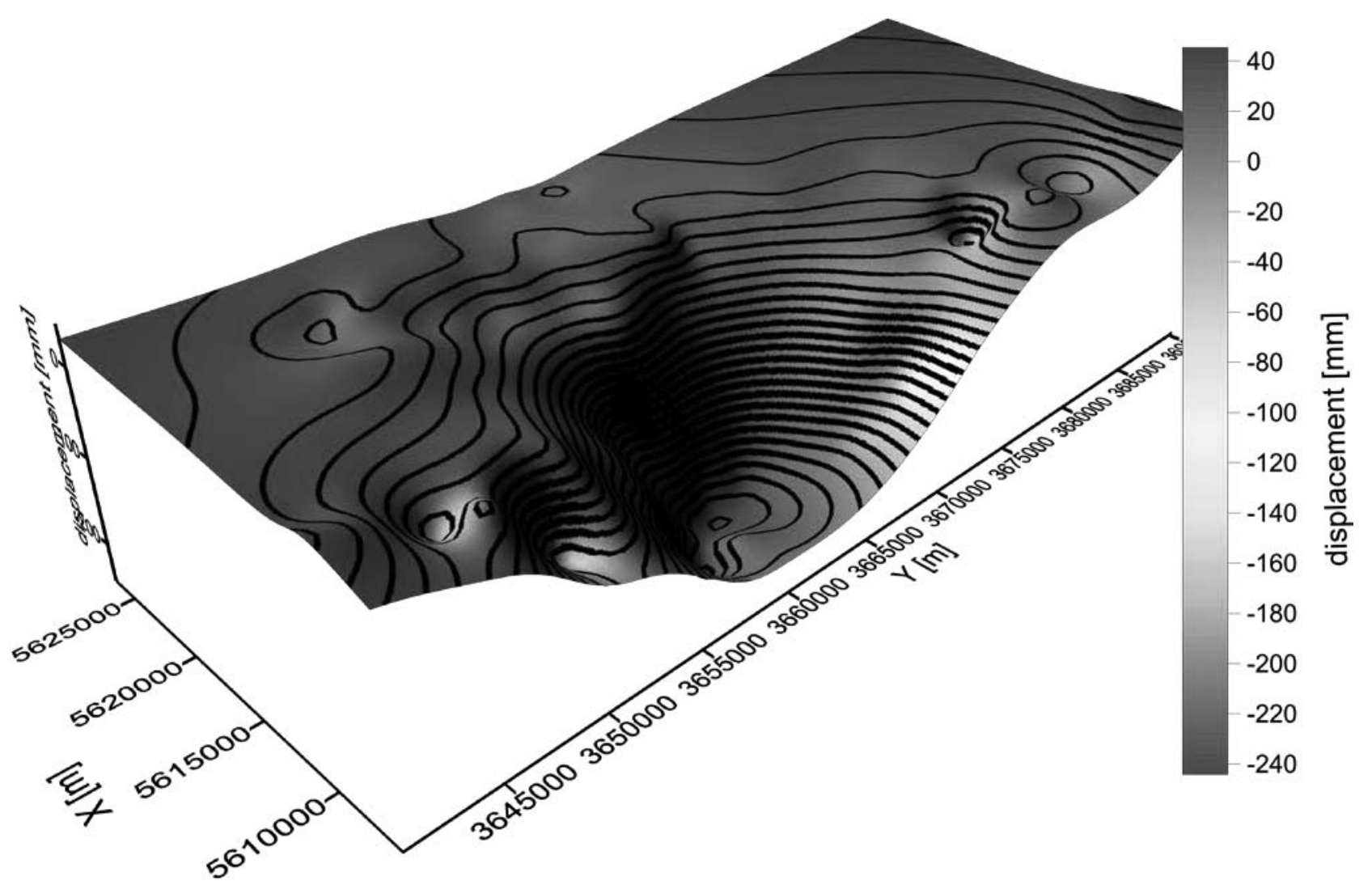

Fig. 4. A geometric model of a land deformation: steepest descent method. 


\section{Conclusions}

The paper presents the possibility of using feedforward neural networks, trained under supervision, for approximation of the process of changes in land surface deformation caused by mining. The neural networks that were used served as a universal approximator, and as a result it was possible to obtain information about changes in land surface occurring in the area under research. The most favourable test results were obtained for a two-layer network with the use of the conjugate gradient method as the training method, and the least favourable results were obtained for the steepest descent method, in which the iteration process very often stopped at local minima. An interesting approach to the problem of training neural networks is the RPROP algorithm, in which the weights are updated dependent on the sign of the gradient components, and its value is disregarded. In the case of this algorithm, the network for which the best result was obtained is a one-layer network, and the results are close to the results obtained by means of the conjugate gradient method.

On the basis of the results presented in the paper it is possible to say that feedforward neural networks work better as instruments for approximating changes in land deformation, and results produced by them are comparable with or slightly better than results obtained with classic methods. An additional advantage of neural networks is the fact that the input set can be updated with additional information such as: the geological structure, ground water level, time interval between geodesic measurements or depth and range of current mining activities, which can reduce the generalization error in the results.

\section{References}

1. W. Duch, J. Korbicz, L. Rutkowski, R. Tadeusiewicz, Sieci neuronowe (Akademicka Oficyna Wydawnicza Exit, Warszawa, 2000)

2. Ch. Lian, Z. Zeng, W.Yao, H.Tang, Engineering Geology, Volume 186, 91-99 (2015)

3. J. Barzykowski (Ed.), Współczesna metrologia. Zagadnienia wybrane (WNT, Warszawa, 2004)

4. R. Hejmanowski, W.T. Witkowski, Journal of Sustainable Mining, 14, 101-107 (2015)

5. W.T. Witkowski, Przegląd Górniczy, 2, 88-94 (2016)

6. M. Mrówczyńska, Studium nad doborem metod inteligencji numerycznej do rozwiazywania problemów z geodezji inżynieryjnej (Oficyna Wydawnicza Uniwersytetu Zielonogórskiego, Zielona Góra, 2015)

7. J. Gil, Przyklady zastosowań sieci neuronowych $w$ geodezji (Oficyna Wydawnicza Uniwersytetu Zielonogórskiego, Zielona Góra, 2006)

8. R. Kadaj, Modele, metody i algorytmy obliczeniowe sieci kinematycznych $w$ geodezyjnych pomiar przemieszczén i dokształcen obiektów (Wydawnictwo Akademii Rolniczej, Kraków, 1998)

9. M. Mrówczyńska, Przegląd Górniczy, 10, 37-41 (2015)

10. N. Jankowski, Ontogeniczne sieci neuronowe. $O$ sieciach zmieniajacych swoja strukture (Akademicka Oficyna Wydawnicza EXIT, Warszawa, 2003) 